\title{
Multicentre trial on feeding low birthweight infants: effects of diet on early growth
}

\author{
A LUCAS, S M GORE,'T J COLE, M F BAMFORD, J F B DOSSETOR, I BARR, L DICARLO, \\ S CORK, AND P J LUCAS
}

Medical Research Council Dunn Nutrition Unit and Biostatistics Unit, Cambridge; Department of Paediatrics, Heath Road Hospital, Ipswich; Department of Paediatrics, Queen Elizabeth Hospital, Kings Lynn; Farley Health Products PLC, Plymouth; Rosie Maternity Hospital, Cambridge

SUMmARY A large multicentre study on the short and long term clinical and developmental outcome of infants randomised to different diets is being undertaken. This report represents an interim analysis of the early postnatal growth performance of an unselected population of 194 preterm infants (gestation, mean (SD) 31.0 (2.9) weeks; birthweight, mean (SD) 1364 (294) g), both ill and well, examined in two (of four) parallel trials. One trial compared banked breast milk with a new preterm formula (primary trial); the other compared these diets as supplements to maternal milk (supplement trial). A major dietary effect on the number of days taken to regain birthweight and subsequent gains in weight, length, and head circumference was observed in the primary trial. Infants fed banked breast milk and weighing less than $1200 \mathrm{~g}$ at birth took a calculated additional three weeks to reach $2000 \mathrm{~g}$ compared with those fed on the preterm formula. A significant influence of diet on body proportions was seen in the relation between body weight, head circumference, and length. Similar though smaller differences in growth patterns were seen in the supplement trial. By the time they reach $2000 \mathrm{~g}$, infants of birthweights 1200 to $1849 \mathrm{~g}$ fed on banked breast milk and infants below $1200 \mathrm{~g}$ fed on either banked breast milk or maternal milk supplemented (as necessary) with banked breast milk, fulfilled stringent criteria for failure to thrive (weight less than 2 SD below the mean for age). Only infants fed the preterm formula as their sole diet had maintained their birth centile by discharge from hospital. The misleading nature of comparisons between extrauterine and intrauterine steady state weight gains is emphasised.

A wide variety of dietary regimens is available for feeding low birthweight infants. The relative merits of different diets have been assessed in numerous studies, largely in terms of their effects on short term growth, metabolism, and nutrient handling. There are, however, few published data on how these short term dietary responses relate to clinical outcome. A major problem has been that the investigation of clinical outcome requires the study of very large populations of subjects. Nevertheless, the paucity of information on the effects of different feeding regimens on short term morbidity and mortality and on long term morbidity, growth, and neurological development makes it difficult for neonatologists to interpret the clinical relevance of many of the published findings on the nutrition of preterm infants.
In view of these considerations we are conducting a large multicentre study, based at the Medical Research Council's Dunn Nutrition Unit and the Cambridge University Department of Paediatrics, in collaboration with five British neonatal units. Six currently employed dietary regimens are being examined in four parallel trials, in each of which infants are randomised to one of two different diets (see below). A principal objective of the study is to investigate in low birthweight infants the influence of early dietary practices on several aspects of clinical and neurodevelopmental outcome, determined by blind evaluation at follow up. Anthropometric, metabolic, and physiological studies are being undertaken during the postnatal period to define the associations, if any, between short term dietary responses and later growth, development, 
and morbidity. The purpose of this paper is to introduce the overall study design and to discuss the results of an early interim analysis of short term anthropometric effects in infants studied to date in two of the clinical trials conducted in three of the five trial centres. The randomised comparisons presented here are between banked donor breast milk and a new preterm infant formula, used as sole diet (primary trial) and between these two diets used as supplements to the mothers own 'preterm' milk (supplement trial).

\section{Patients and methods}

Overall study design. The study is being conducted in five centres-Cambridge, Ipswich, Kings Lynn, Norwich, and Sheffield. Only the first three of these are considered in this paper, but the study design applies to all. All infants less than $1850 \mathrm{~g}$ admitted to the special care baby unit at each centre are entered into the trial regardless of whether they are well or ill; the two criteria for exclusion are lack of parental consent after full explanation (no cases to date) or a severe congenital abnormality known to influence growth or neurological development. Infants are studied in the postnatal period until they leave the neonatal unit (to go home or by being transferred to a non-trial unit, or die) or when they reach $2000 \mathrm{~g}$, whichever is the sooner. Parental consent is sought for clinical and developmental follow up, to 18 months in the first instance: this includes Bayley developmental testing. Over 500 infants were entered into the trial during its first two years.

It was not considered acceptable to influence a mother's choice as to whether or not she wished to provide her own milk for the infant; consequently there are two parallel clinical trials at each centre (see Table 1). In the first three centres, for example, infants are fed on banked breast milk for up to 48 hours postnatally while mothers decide whether to express breast milk. If the mother elects not to express breast milk her infant is entered into the primary trial and randomly allocated to either banked pooled donor breast milk (mainly drip breast milk, fed at up to $200 \mathrm{ml} / \mathrm{kg} / 24$ hours) or a new preterm infant formula (fed at up to $180 \mathrm{ml} / \mathrm{kg} / 24$ hours), as sole diet. If the mother decides to feed her baby, the infant is entered into the supplement trial and is randomly allocated to banked breast milk or the preterm formula as a supplement to ensure a daily enteral intake of up to $200 \mathrm{ml} / \mathrm{kg} /$ day by the time full enteral feeds have been achieved. In the supplement trial infants may receive, according to maternal inclination or success in expressing breast milk, any proportion of the supplement in their diet from 0 to $100 \%$ : the median intake of breast milk in the two supplement groups being $42 \%$ (only $21 \%$ of mothers provided more than $80 \%$ of their infants' total requirements, and $38 \%$ provided less than $20 \%$ of their infants' needs). When greater numbers of

Table 1 Descriptive statistics of infants in the primary trial (fed preterm formula (PTF) or banked breast milk (BBM) only) and the supplement trial (fed expressed breast milk (EBM) plus PTF or BBM)

\begin{tabular}{|c|c|c|c|c|}
\hline & \multicolumn{2}{|c|}{ Primary trial } & \multicolumn{2}{|c|}{ Supplement trial } \\
\hline & $\begin{array}{l}P T F \\
(n=33)\end{array}$ & $\begin{array}{l}B B M \\
(n=29)\end{array}$ & $\begin{array}{l}E B M+P T F \\
(n=65)\end{array}$ & $\begin{array}{l}E B M+B B M \\
(n=67)\end{array}$ \\
\hline No of infants with birthweight less than $1200 \mathrm{~g}$ & 12 & 8 & 16 & 18 \\
\hline \multicolumn{5}{|l|}{ Gestational age (weeks), mean (SD) } \\
\hline Overall & $30 \cdot 8(3 \cdot 0)$ & $31 \cdot 6(3 \cdot 1)$ & $31 \cdot 3(2 \cdot 7)$ & $30 \cdot 6(2 \cdot 9)$ \\
\hline Less than $1200 \mathrm{~g}$ & $28 \cdot 1(2 \cdot 0)$ & $29 \cdot 0(2 \cdot 3)$ & $29 \cdot 1(2 \cdot 3)$ & $27 \cdot 4(1 \cdot 2)$ \\
\hline $1200-1849 \mathrm{~g}$ & $32 \cdot 3(2 \cdot 3)$ & $32 \cdot 5(2 \cdot 9)$ & $32 \cdot 0(2 \cdot 4)$ & $31 \cdot 8(2 \cdot 4)$ \\
\hline \multicolumn{5}{|l|}{ Birthweight (g), mean (SD) } \\
\hline Overall & $1371(292)$ & $1431(325)$ & $1406(281)$ & $1353(295)$ \\
\hline Less than $1200 \mathrm{~g}$ & $1068(121)$ & $984(153)$ & $1021(133)$ & $953(151)$ \\
\hline $1200-1849 \mathrm{~g}$ & $1545(205)$ & $1601(171)$ & $1531(185)$ & $1501(172)$ \\
\hline Head circumference $(\mathrm{OFC})$ in first week $(\mathrm{mm})$, mean $(\mathrm{SD})$ & $277(21)$ & $280(25)$ & $278(18)$ & $276(22)$ \\
\hline Length in first week $(\mathrm{mm})$, mean $(\mathrm{SD})$ & $402(24)$ & $396(37)$ & $406(30)$ & $399(32)$ \\
\hline \multicolumn{5}{|l|}{ No of infants } \\
\hline Born as singletons & 27 & 19 & 55 & 49 \\
\hline Birthweight $<10$ th centile for gestational age* & 8 & 7 & 14 & 11 \\
\hline Requiring resuscitation (with intubation) at birth & 12 & 14 & 38 & 31 \\
\hline Requiring mechanical ventilation & 17 & 14 & 25 & 31 \\
\hline Delivered by caesarean section & 18 & 7 & 32 & 38 \\
\hline Whose mothers had toxaemia or hypertension ${ }^{\dagger}$ & 10 & $7^{+}$ & $18^{+}$ & 16 \\
\hline Whose mothers were primiparae ${ }^{\ddagger}$ & 10 & $6^{\frac{1}{+}}$ & 33 & 35 \\
\hline Requiring $>10$ days to achieve full enteral feeds & 8 & 8 & 15 & 16 \\
\hline Requiring a period of total parenteral nutrition & 2 & 4 & 3 & 4 \\
\hline Enteral feed volume by week $3(\mathrm{ml} / \mathrm{kg} / \mathrm{d})$, mean (SD) & $167(9)$ & $192(8)$ & $169(6)$ & $179(6)$ \\
\hline
\end{tabular}

${ }^{*}$ Lubchenko. ${ }^{1}$

${ }^{+}$Maternal toxaemia or hypertension unknown in two cases; ${ }^{\ddagger}$ maternal parity unknown for one infant. 
subjects have been studied it will be possible to post-stratify the supplement trial according to the proportion of supplement received. (In the two centres (Norwich and Sheffield) not discussed in this paper, the comparison is between a 'standard' and a 'preterm' infant formula either as sole diet or as supplement).

A balanced randomisation sequence was prepared for each centre, within strata defined by birthweight: less than $1200 \mathrm{~g}$ and 1200 to $1849 \mathrm{~g}$. Treatment assignments were held in sealed numbered envelopes in the three neonatal units. No attempt has been made to blind clinical staff to the type of diet employed as the diets are distinguishable in practice and in a pragmatic study of this nature it is important that any effects of the diet per se on clinical management are allowed to operate. In the centres under discussion, well infants are fed enterally from 2 to 3 hours of age. In sicker infants intravenous infusion is stopped and enteral feeds are gradually increased, as tolerated. Only those infants with very severe respiratory disease or who are extremely immature at birth, and those who develop necrotizing enterocolitis are fully intravenously fed for a period (see Table 1).

The target infant accrual figures for a four group sequential design ${ }^{2}$ with $90 \%$ power of detecting a difference in weight gain in the primary trial of 3.8 $\mathrm{g} / \mathrm{kg} /$ day and of $2 \cdot 5 \mathrm{~g} / \mathrm{kg} / \mathrm{day}$ in the supplement trial were calculated from a pilot study of short term anthropometric responses undertaken at Cambridge in 1981. Accordingly, interim analyses were planned after each group of 32 infants randomised in the primary trial and of 72 infants in the supplement trial. (This report is the second interim analysisfirst 16 months accrual). Sample size for other responses was estimated, where possible from published information. Although the investigation of short term growth is not the principal objective of this trial, we have chosen it as a primary response since the establishment of major growth differences between groups is an important prerequisite for relating early growth to later clinical outcome.

Data include detailed records of obstetric and perinatal events, clinical course, and anthropometry. A variety of biochemical, nutritional, and immunological studies are being carried out concurrently. In infants fed human milk (banked or mothers' own), a sample is collected from each pooled 24 hour milk collection so that precise intakes may be computed for individual infants. Work is conducted at each centre by a research nurse and a paediatrician. Anthropometry is always carried out by the same personnel in each centre, after a 'run in' period to minimise intercentre variation in measurements.
Table 2 Macronutrient composition of banked breast milk (340 samples of pooled collections) and preterm formula (Osterprem)

\begin{tabular}{lll}
\hline & Preterm formula & $\begin{array}{l}\text { Banked breast milk } \\
\text { Mean }(S D)\end{array}$ \\
\hline Energy $(\mathrm{kcal} / 100 \mathrm{ml})$ & 80 & $46(7)$ \\
Protein $(\mathrm{g} / 100 \mathrm{ml})^{*}$ & $2 \cdot 00$ & $1 \cdot 07(0 \cdot 20)$ \\
Carbohydrate $(\mathrm{g} / 100 \mathrm{ml})$ & $7 \cdot 0$ & $7 \cdot 1(0 \cdot 9)$ \\
Fat $(\mathrm{g} / 100 \mathrm{ml})$ & $4 \cdot 89$ & $1 \cdot 70(0 \cdot 58)$ \\
Sodium $(\mathrm{mmol} /)$ & $19 \cdot 6$ & $6 \cdot 8(0 \cdot 2)$ \\
Potassium $(\mathrm{mmol} / \mathrm{l})$ & $16 \cdot 7$ & $14 \cdot 3(2 \cdot 0)$ \\
Calcium $(\mathrm{mg} / 100 \mathrm{ml})$ & 70 & $(35)^{*}$ \\
Phosphorus $(\mathrm{mg} / 100 \mathrm{ml})$ & 35 & $(15)^{4}$ \\
\hline
\end{tabular}

*Total nitrogen $\times 6 \cdot 38$

${ }^{+}$Not determined by us: figures from DHSS report on the comparison of mature human milk. ${ }^{3}$

Ethical approval for the study has been obtained from the ethical committee at each hospital.

Subjects and diets. At the time of interim analysis 194 preterm infants (gestation, mean (SD) $30 \cdot 7(2 \cdot 8)$ weeks and birthweight 1364 (301) g) had been studied at the first three centres (for breakdown see Table 1). The average macronutrient composition of 340 pools of banked breast milk is shown in Table 2 . Our analytic data on maternal milk are to be published elsewhere. We designed a new preterm formula for this study (Osterprem, specially manufactured by Farley Health Products PLC) and its macronutrient composition is also shown in Table 2. The results considered in the present report are measurements of days to regain birthweight, subsequent weight gain in steady state and its relation to centile charts, together with length and head circumference gain and their relation to body weight. Weight was measured daily to $1 \mathrm{~g}$ accuracy using an electronic balance (Sartorius MP models) which computes the average of serial weighings to reduce infant movement artefact. Occipitofrontal head circumference was measured by paper tape, and crown to heel length by use of a horizontal stadiometer; both to the next succeeding $\mathrm{mm} .{ }^{4}$ Both head circumference and length were measured twice each week (minimum, once each week). Head circumference and length gain were calculated by linear regression of all available measurements made over at least two weeks after regaining birthweight (regaining birthweight was defined as the first of three consecutive days above weight at birth).

\section{Results}

Study population. Details of the study population are shown in Table 1. Infants in each trial (primary and supplement) were well matched for gestation, 


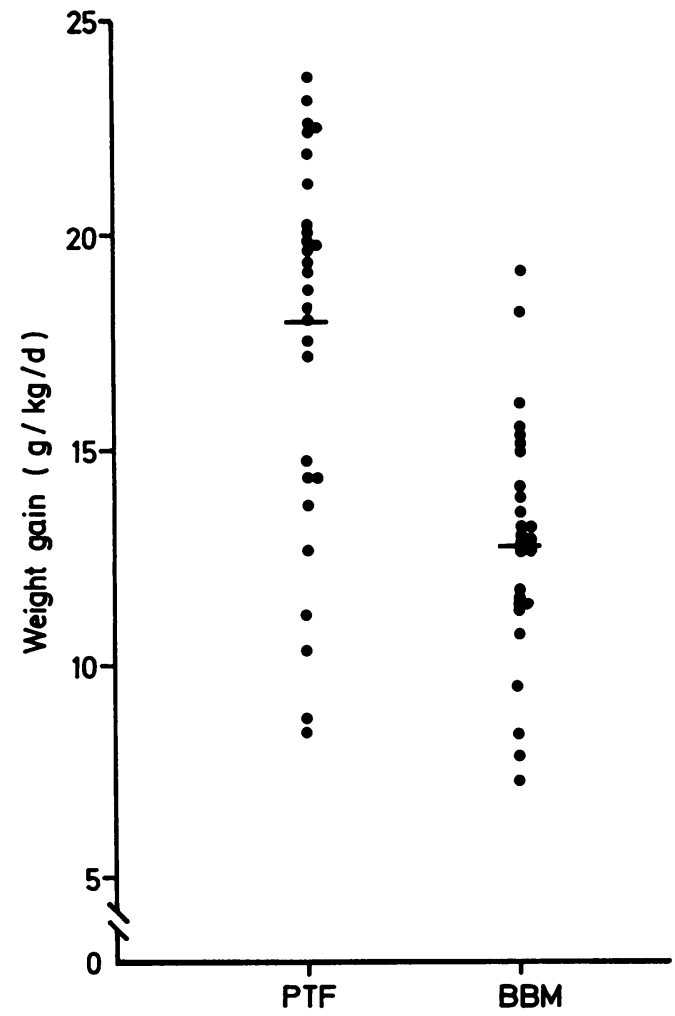

Fig. 1 Individual weight gains ( $\mathrm{g} / \mathrm{kg} /$ day) after regaining birthweight in infants fed on preterm formula $(P T F)$ and banked breast milk (BBM).

Two infants, initially randomly assigned to PTF are not included in Fig. 1: one who died aged 6 days was grossly oedematous (weight gain: $39 \mathrm{~g} / \mathrm{kg} / \mathrm{day}$ ) and had never been fed and a second infant was withdrawn before regaining birthweight from the PTF fed group on the clinician's request and was fed on BBM (weight gain: $6 \cdot 3 \mathrm{~g} / \mathrm{kg} /$ day).

birthweight, need for mechanical ventilation or intravenous infusions, incidence of small for dates status, maternal parity, and incidence of maternal toxaemia or hypertension. In the primary trial, where accrual numbers are smaller, there was a tendency to a lower proportion of boys on banked breast milk, and a larger proportion of infants on the preterm formula had been delivered by caesarean section. Regression analysis, however, showed (see below) that sex or mode of delivery, or both, did not significantly adjust the growth performance differences between the randomised feed groups in the primary trial. Table 1 shows that the mothers who chose to feed their infants (supplement trial) differed significantly in parity from those who did not $\left(\chi_{(1)}^{2}=9 \cdot 85 ; P=0 \cdot 002\right)$.
Growth performance. Tables 3 and 4 show differences in growth performance between feed groups. There were significant differences in the primary trial between banked breast milk and preterm formula fed infants (in favour of the preterm formula) in respect of days to regaining birthweight, weight gain (mean (SE), 12.8 (0.5) v $18.0(1.1)$ $\mathrm{g} / \mathrm{kg} /$ day), length gain (mean (SE), 1.04 (0.09) v 1.38 $(0.09) \mathrm{mm} /$ day) and head circumference gain (mean (SE) $1.23(0.08) v 1.57(0.10) \mathrm{mm} /$ day). Individual weight gains are shown in Fig. 1. In the supplement trial significance was reached for greater weight and length gain in formula fed infants, with a trend in this group towards an increased head circumference gain and a shorter period to regaining birthweight. Weight gain in infants below the 10th centile for weight (using Lubchenko charts ${ }^{4}$ ) (Table 4) did not differ significantly from that in infants who were appropriate for dates. Preliminary work on regression modelling to take account of those covariates shown in Table 1 suggests that head circumference gain in the primary trial was influenced by gestation, and days to regain birthweight by the mode of delivery. Weight gain in the supplement trial was influenced by maternal preeclampsia. Taking account of marginal differences in the distribution of covariates between randomised feed groups, however, neither abolished the significant differences shown in Table 3 nor resulted in the emergence of differences not seen by examination of the raw data.

Table 3 Growth performance of infants in the primary and supplement trials

\begin{tabular}{|c|c|c|c|c|}
\hline & \multicolumn{2}{|c|}{ Primary trial } & \multicolumn{2}{|c|}{ Supplement trial } \\
\hline & $P T F$ & $B B M$ & $E B M+P T F$ & $E B M+B B M$ \\
\hline \multicolumn{5}{|c|}{ Days to regain birthweight } \\
\hline Median & 10 & 16 & 13 & 15 \\
\hline No & 33 & 29 & 65 & 67 \\
\hline Log rank test, $\chi_{(1)}^{2}$ & I & & $P=0 \cdot 14$ & \\
\hline \multicolumn{5}{|c|}{ Steady state weight gain } \\
\hline Mean (g/kg/day) & $18 \cdot 0$ & $12 \cdot 8$ & $16 \cdot 3$ & $14 \cdot 3$ \\
\hline SE & $1 \cdot 1$ & $0 \cdot 5$ & $0 \cdot 6$ & 0.4 \\
\hline No & 30 & 28 & 56 & 59 \\
\hline$t$ test & \multicolumn{2}{|c|}{$\mathrm{P}<0.001$} & \multicolumn{2}{|c|}{$\mathrm{P}<0.01$} \\
\hline \multicolumn{5}{|c|}{ Head circumference (OFC) gain } \\
\hline Mean (mm/day) & 1.57 & $1 \cdot 23$ & 1.44 & $1 \cdot 35$ \\
\hline SE & 0.52 & $0 \cdot 39$ & 0.41 & 0.39 \\
\hline No & 25 & 23 & 43 & 54 \\
\hline$t$ test & \multicolumn{2}{|c|}{$\mathrm{P}<0.02$} & \multicolumn{2}{|c|}{$\mathrm{P}=0.33$} \\
\hline \multicolumn{5}{|l|}{ Length gain* } \\
\hline Mean (mm/day) & $1 \cdot 38$ & $1 \cdot 04$ & $1 \cdot 37$ & $1 \cdot 20$ \\
\hline SE & $0 \cdot 09$ & 0.09 & $0 \cdot 07$ & $0 \cdot(04$ \\
\hline No & 12 & 14 & 20 & 25 \\
\hline$t$ test & \multicolumn{2}{|c|}{$\mathrm{P}<0.02$} & \multicolumn{2}{|c|}{$\mathrm{P}<0.05$} \\
\hline
\end{tabular}

${ }^{*}$ Reduced sample size because of delay in phasing length measurement (after intercentre standardisation) into the trial.

PTF $=$ preterm formula; $\mathbf{B B M}=$ banked breast milk: $E B M=$ expressed breast milk. 
Table 4 Growth performance: further results

\begin{tabular}{|c|c|c|c|c|}
\hline & \multicolumn{2}{|c|}{ Primary trial } & \multicolumn{2}{|c|}{ Supplement trial } \\
\hline & PTF & $B B M$ & $E B M+P T F$ & $E B M+B B M$ \\
\hline \multicolumn{5}{|c|}{ Days to regain birthweight stratified by birthweight } \\
\hline Median & 12 & 18 & 16 & 18 \\
\hline No & 12 & 8 & 16 & 18 \\
\hline \multicolumn{5}{|c|}{$12(0)-1849 \mathrm{~g}$} \\
\hline Median & 8 & 15 & 12 & 14 \\
\hline No & 21 & 21 & 49 & 49 \\
\hline
\end{tabular}

Steady state weight gain stratified by birthweigh

Less than 1200 )

$\begin{array}{lllll}\text { Mean }(\mathrm{g} / \mathrm{kg} / \mathrm{d}) & 19.9(19.2)^{\circ} & 14.1 & 15.2 & 13.5\end{array}$

$\begin{array}{lllll}\mathrm{SE} & 2.8(1.6) & 0.8 & 1.4 & 0.6\end{array}$

$\begin{array}{lllll}\text { No } & 10(8) & 8 & 13 & 15\end{array}$

$1200-1849 \mathrm{~g}$

$\begin{array}{lllll}\text { Mean }(\mathrm{g} / \mathrm{kg} / \mathrm{d}) & 17 \cdot 0 & 12 \cdot 3 & 16 \cdot 6 & 15 \cdot 2\end{array}$

SE

2)

43

Steady state weight gain in small for dates subgroup*

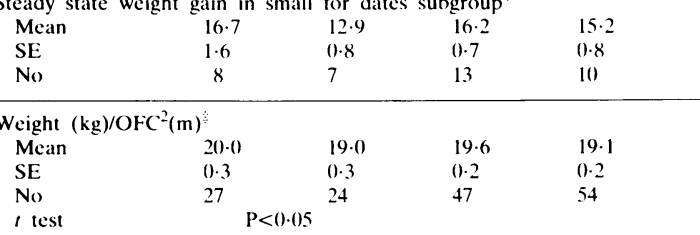

Weight $(\mathrm{kg}) /$ length $^{2}$

$(\mathrm{m})^{4}$

$\begin{array}{lllll}\text { Mean } & 9.8 & 9.4 & 9.9 & 9.8\end{array}$

$\begin{array}{lllll}\mathrm{SE} & 0 \cdot 1 & 0 \cdot 1 & 0 \cdot 1 & 0.1\end{array}$

No

$t$ test

$14 \quad 19$

31

34

Model calculations: day to reach $2000 \mathrm{~g}$ for infant born at

28 wks weighing

$\begin{array}{lllll}10(K) \mathrm{g} & 47 & 68 & 62 & 70\end{array}$

32 whs weighing

15() $0 \mathrm{~g}$

25

39

30

35

${ }^{*}$ Less than 10 th centile for gestational age (Lubchenko).

Data in parentheses excluding the two infants discussed in footnote of Fig. 1 .

Last measurements before discharge at weight $>1.7 \mathrm{~kg}$ (NB the smaller the ratio the larger the head or length in relation to body weight).

$\mathrm{PTF}=$ preterm formula, $\mathrm{BBM}=$ banked breask milk, EBM=expressed breast milk, $O F C=$ occipitefrontal head circumference.

To determine whether or not the interrelation between weight gain and gains in head circumference (OFC) or length differed between feed groups, two ratios have been used, namely:

$$
\frac{\mathrm{wt}(\mathrm{kg})}{\mathrm{OFC}^{2}(\mathrm{~m})} \text { and } \frac{\mathrm{wt}(\mathrm{kg})}{\text { length }^{2}(\mathrm{~m})}
$$

These have been applied to the last set of anthropometric measurements made before the infant was discharged from the study (provided that a weight of $1700 \mathrm{~g}$ had been exceeded at this point). These power ratios have been selected on the basis of the arguments of Cole et al ${ }^{5}$-it has been assumed that in relation to weight gain, the increase in head circumference behaves in a similar way to length gain. The ratios are provisional, however, until we have more data on the precise relation between these variables. Formula fed infants compared with the banked breast milk fed group in the primary feed trial had significantly lower ratios of:

$$
\begin{aligned}
& \text { wt }(\mathrm{kg}) \quad(\text { mean }(\mathrm{SEM}) 20 \cdot 0(0 \cdot 3) \text { versus } \\
& \left.\overline{\mathrm{OFC}^{2}(\mathrm{~m})} \quad 19 \cdot 0(0 \cdot 3), \mathrm{P}<0 \cdot 01\right) \\
& \text { and } \\
& \text { wt }(\mathrm{kg}) \quad(\text { mean }(\mathrm{SEM}) 9 \cdot 8(0 \cdot 1) \text { versus } \\
& \left.\overline{\text { length }^{2}(\mathrm{~m})} \quad 9 \cdot 4(0 \cdot 1), \mathrm{P}<0 \cdot 05\right) \text {. }
\end{aligned}
$$

Similar trends were seen in the supplement trial but significance was not reached (Table 4).

\section{Model anthropometric calculations for weight gain}

The weight and gestation of infants below and above $1200 \mathrm{~g}$ were mean (SD), $1003(143) \mathrm{g}$ at $28 \cdot 3(2 \cdot 0)$ weeks and $1533(183) \mathrm{g}$ at $32 \cdot 1(2 \cdot 5)$ weeks respectively. Thus, for the model calculations, 'typical' infants of $1000 \mathrm{~g}$ at 28 weeks' gestation and $1500 \mathrm{~g}$ at 32 weeks' were chosen. We derived, from days to regain birthweight and subsequent weight gain, the expected time to attain $2000 \mathrm{~g}$ (a figure near to that chosen by many units as a suitable weight for discharge home). Data on the actual number of days to discharge are not presented here since a proportion of infants $(16 \%)$ were discharged to other hospitals before reaching $2000 \mathrm{~g}$. Also, we identified a small effect of diet on discharge weight: some infants fed banked breast milk being discharged slightly lighter than those fed on the preterm formula. Since our population data confirm, however, that weight gain in $\mathrm{g} / \mathrm{kg} /$ day is linear, data from infants who were discharged in this way have been incorporated into the model calculations. Calculated days to $2000 \mathrm{~g}$ are shown in Table 4. Fig 2 (a) and (b) shows that $1000 \mathrm{~g}$ and $1500 \mathrm{~g}$ 'model' infants fed preterm formula had maintained their birth centile at $2000 \mathrm{~g}$, whereas all other groups had fallen below the 10th centile at this weight, and $1000 \mathrm{~g}$ infants fed on banked breast milk or expressed breast milk plus banked breast milk and $1500 \mathrm{~g}$ infants fed on banked breast milk fell below the third centile. (Lubchenko charts for both sexes combined have been used ${ }^{4}$ ). Calculated weight gain performance matches our data on actual days to achieve given weights in those remaining in the study at that point. For comparison with the model calculations Fig. 2 (c) shows the actual growth patterns of two infants from the primary trial, one fed on preterm formula (birthweight $1162 \mathrm{~g}$ ), the other on banked breast milk $(1200 \mathrm{~g})$. These infants were selected on the predetermined basis that they were the representatives of their feed group lying nearest to the 50th centile at 28 weeks' gestation. Both infants required mechanical ventilation for two 

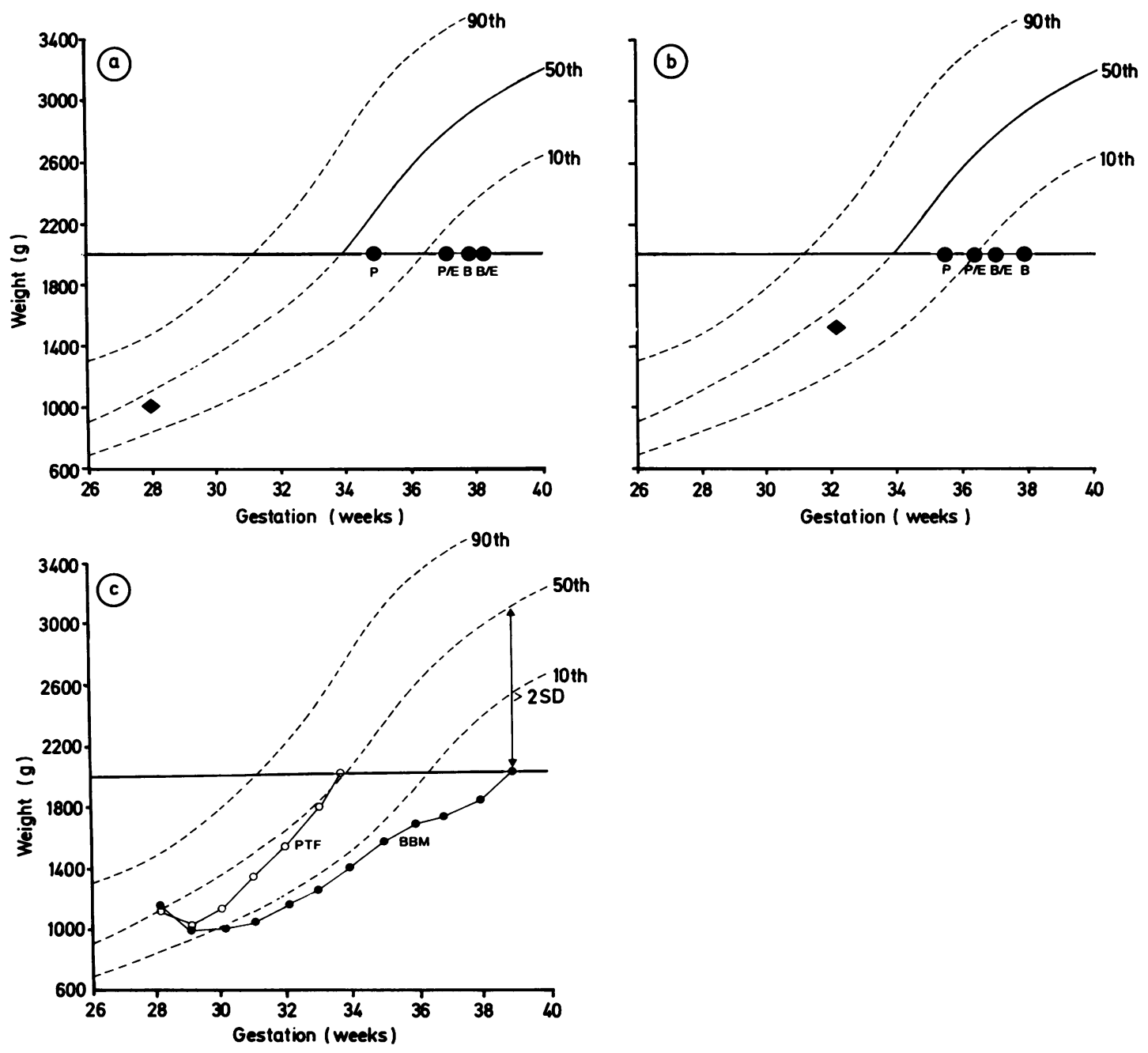

Fig. 2 (a) and (b) Calculated position on a weight for gestational age chart (Lubchenko') at $2000 \mathrm{~g}$ bodyweight according to diet for an infant of birthweight $1 \mathrm{~kg}$ born at 28 weeks' gestation and one of birthweight $1.5 \mathrm{~kg}$ born at 32 weeks' gestation.

Fig. 2 (c) The actual growth performance of two infants with birthweights near the 50th centile at 28 weeks' gestation, one fed on preterm formula (PTF) the other on banked breast milk (BBM).

In Fig 2 (a) and (b) indicates starting weight for gestational age and $\bigcirc$ indicates the final position at $2000 \mathrm{~g}$. $\mathrm{P}=$ preterm formula alone; $\mathrm{B}=$ banked breast milk alone; and $\mathrm{E}=$ expressed maternal 'preterm' milk supplemented by either B or P. In Fig. 2 (c) weights at birth and at the end of each week until reaching $2000 \mathrm{~g}$ are plotted.

days. Fig 2 (c) illustrates the catch up growth of the infant fed preterm formula, resulting in a return to the birth centile by $2000 \mathrm{~g}$ : in contrast, the infant fed banked breast milk regained birthweight more slowly and his weight diverged progressively from the 50th centile, lying more than 2 SD below this centile at $2000 \mathrm{~g}$.

The observation that the average birthweight for infants in this study lies on the 25 th rather than the 50th centile may be in part an artefact, since the weight exclusion criterion for the study would tend to eliminate infants on the higher centiles.

\section{Discussion}

Several investigators have reported significant differences in the growth performance of preterm infants fed on different diets. ${ }^{6-8}$ If more rapid 
postnatal growth were to reduce the period of hospital stay without an attendant increase in short or long term risks to the infant, then clearly, on social and financial ground alone, there would be a strong case for the use of growth promoting diets (assuming that weight rather than postnatal age were to be taken as the criterion for discharge home). This case would be strengthened greatly were it to be shown that diets inducing lower growth rates resulted in impaired long term growth or neurological development. At present, however, such arguments are speculative. There have been no published studies that have been either large enough or of sufficient duration to provide adequate reassurance on the short and long term clinical safety of modern, growth promoting diets, especially when fed to sick infants. Likewise the long term consequences of diet related extrauterine growth retardation in the early postnatal weeks have not been explored satisfactorily, though preliminary work in this area is emerging. ${ }^{9}$ One purpose of this interim analysis of short term anthropometric data is to provide a basis for the investigation of the relation between early growth performance on different diets and later outcome (which is being examined currently at follow up).

Three aspects of our study design require special consideration. Firstly, in some dietary studies sick infants have been excluded to reduce variability in growth performance and thus permit the use of small sample sizes; in this study an unselected population has been examined (major congenital abnormality being the only exclusion criterion). Secondly, it is our objective to explore the effects of current feeding practices in epidemiological terms (rather than to adopt a more experimental approach using specially designed feeds). The most common regimen employed by many units is to combine maternal milk with another diet (such as donor milk or formula), yet this type of regimen has been studied little in clinical trials. In our experience mothers' preterm milk, which has received much recent attention, ${ }^{810} 11$ is often not produced in sufficient quantities to be used as a sole diet. ${ }^{12}$ For this reason we have examined the use of maternal milk in the context of a 'supplement trial'. Thirdly, although epidemiological comparisons may be made between infants in the 'primary trial' and those in the 'supplement trial', it is only within each trial that a randomised comparison is being made; indeed our preliminary evidence suggests that the population of mothers who choose to feed their own infants differs from those who do not and this may complicate the interpretation of published data-involving the nonrandomised comparison of infants fed on maternal milk with those fed on other diets.
Our findings show that infants fed on a preterm formula regain their birthweight 6 days earlier (median) than infants fed on higher volumes of banked drip breast milk, and gain weight subsequently at a rate $(18 \mathrm{~g} / \mathrm{kg} / \mathrm{day})$ well in excess of the reported intrauterine growth rate on the 50th centile of $14.4 \mathrm{~g} / \mathrm{kg} / \mathrm{day},{ }^{4}{ }^{13}$ compared with a significantly lower rate of $12.8 \mathrm{~g} / \mathrm{kg} /$ day in the banked breast milk fed group. The subgroup of formula fed infants with birthweights below $1200 \mathrm{~g}$ showed a tendency to even faster growth rates $(19.9 \mathrm{~g} / \mathrm{kg} /$ day $)$, and in spite of the fact that a significant proportion of these neonates were sick they regained birthweight in a median time of 12 days, little over the time taken by a term infant and compared with 18 days on banked breast milk. In the supplement trial, infants fed on the formula as a supplement to maternal milk gained weight faster than the intrauterine rate $(16.3 \mathrm{~g} / \mathrm{kg} /$ day), whereas those supplemented with banked breast milk gained weight near to this rate $(14 \cdot 2$ $\mathrm{g} / \mathrm{kg} /$ day). When 'model' weight gain performance for a $1.0 \mathrm{~kg}$ and a $1.5 \mathrm{~kg}$ infant (at 28 and 32 weeks' gestation respectively) is plotted on a centile chart, however, it is clear that only infants fed on the preterm formula as a sole diet had regained their birth centile at $2000 \mathrm{~g}$. In the $1 \mathrm{~kg}$ model, by weight $2000 \mathrm{~g}$, infants fed on preterm formula as a supplement to expressed breast milk fall below the 10th centile and those fed on banked breast milk either as a sole diet or as a supplement fall to over two standard deviations below the mean and thus fulfil a stringent criterion for 'failing to thrive'. Similarly, in the $1.5 \mathrm{~kg}$ model the infants fed on banked breast milk as a supplement to maternal milk fall below the 10th centile and those fed on banked breast milk alone fall to around the third centile ( 2 SD below the mean). These data serve to emphasise the misleading nature of comparisons with intrauterine growth rate. A critical factor with respect to performance on centile charts is time to regain birthweight. If this is prolonged not only will the infant need to exhibit catch up growth (at a rate substantially faster than that seen in utero) but, as the infant drops to a lower centile during the non-growing phase, he will need to gain weight at a faster rate simply to maintain his position on the lower centile (the intrauterine growth rate on the 10th centile is greater than that on the 50th). ${ }^{13}$

Small for dates preterm infants were included in the study population. There was, however, surprisingly little difference between their weight gain and that of the whole population in each diet group.

In the primary trial the preterm formula promoted significantly faster rates of head circumference and length gain than those seen in infant's fed banked breast milk. A smaller but significant 
increase in length gain together with a trend towards increased head growth was seen in infants fed on preterm formula used as a supplement to expressed breast milk, when compared with those in the banked breast milk supplement group. Our preliminary work suggests that a range of factors, including birthweight, influence length gain so that comparisons between published trials ${ }^{69}$ are difficult. Infants fed on the same preterm formula who have entered the trial to date in the last two centres (not discussed in this paper) were found to have a mean rate of length gain of $10.9 \mathrm{~mm} /$ week compared with $9.7 \mathrm{~mm} /$ week in this study. The data presented here refer to length gain after regaining birthweight, but it is interesting to note that infants frequently gain length considerably before this point.

As accrual into the trials increases it will be possible to analyse in more detail the influence of diet on certain subgroups, for example infants with prolonged respiratory disease. Our initial experience with regression analysis indicates that the analysis of covariate effects will help to explain the considerable individual variation in growth performance (see Fig. 1).

A preliminary examination of the relation between head circumference and length with body weight at the time of discharge from the study (Table 4) indicates that in the primary trial, infants fed preterm formula are slightly heavier in relation to their length and head circumference than those fed on banked breast milk. (Nevertheless, our unpublished data suggest that in infants fed banked breast milk, head circumference and length both lie on a lower centile than those for preterm formula fed infants). This observation may indicate a tendency to increased fat or water accretion, or both, in the preterm formula fed group: we have insufficient information at present to substantiate this with respect to body fat (though it has been reported by others ${ }^{14}$ ), but our early findings suggest a marginal increase in total body water content in this group (determined by a stable isotope method). Alternatively, our findings might reflect a relative preservation of head and length growth in the banked breast milk group in response to failure to thrive.

The explanation for the growth difference between the groups is likely to be multifactorial. Compared with human milk, the preterm formula (in accordance with calculated intake requirements for low birthweight infants) contains higher concentrations of protein, fat, energy, sodium, calcium, phosphorus, and certain trace elements and vitamins-all of which might influence growth performance. It is likely that the increased protein intake in the preterm formula fed group (the preterm formula contains twice the protein concentration found in banked breast milk) played a major role in this respect. Poor growth performance of low birthweight infants fed human milk has been observed by others. ${ }^{6}{ }^{15}$ The more optimistic reported findings, however, on the growth of infants fed on their own mother's preterm milk ${ }^{8}$ are not reflected in the observations presented in this study (particularly with respect to the smallest infants); indeed preliminary data from a small subpopulation of 15 infants from the supplement trial who had received at least $95 \%$ of their total intake as maternal milk, gained weight at only $14 \mathrm{~g} / \mathrm{kg} / \mathrm{day}$, with lower rates of head circumference and length gain than those in the preterm formula group. Our interim data predict that whatever type of human milk is selected, a $1 \mathrm{~kg}$ infant could be expected to take in the region of three weeks longer to reach $2000 \mathrm{~g}$ than one fed on preterm formula. Thus, in those units that use weight as a criterion for discharge, human milk fed infants will have a considerably prolonged hospital stay; but even when an early discharge policy is adopted, breast fed infants may perhaps continue to grow slowly at home, at least to $2000 \mathrm{~g}$.

The follow up of these infants will provide clinical information on whether or not low neonatal growth rates are detrimental in the long term.

We thank Professor J A Davis and Dr R G Whitehead for help and encouragement; the staff of the special care baby units at Cambridge, Ipswich, and Kings Lynn for their assistance and cooperation: Farley Health Products for the manufacture of the preterm formula and financial and technical assistance; and Mr G Hudson for analytical data on banked breast milk.

\section{References}

1 Lubchenko LO, Hansman C, Dressler M, Boyd E. Intrauterine growth as estimated from liveborn birthweight data at 24 to 42 weeks of gestation. Pediatrics 1963:32:793-800.

2 Pocock SJ. Group sequential methods in the design and analysis of clinical trials. Biometrika 1977;64:191-9.

3 Department of Health and Social Security. The composition of mature human milk. Report on health and social subjects no 12 . London: HMSO, 1977.

4 Davies DP, Holding RE. Neonatometer: a new infant length measurer. Arch Dis Child 1972;47:938.

5 Cole TJ. A method for assessing age-standardized weight-forheight in children seen cross-sectionally. Ann Hum Biol 1979;6:249-68.

6 Brooke OG, Wood C, Barley J. Energy balance, nitrogen balance and growth in preterm infants fed expressed breast milk, a premature infant formula, and two low-solute adapted formulac. Arch Dis Child 1982;57:898-904.

7 Atkinson SA, Bryan MH, Anderson GH. Human milk feeding in premature infants: protein, fat and carbohydrate balances in the first two weeks of life. J Pediatr 1981;99:617-24.

* Gross SJ. Growth and biochemical response of preterm infants fed human milk or modified infant formula. $N$ Engl $J$ Med 1982:308:237-41. 
730 Lucas, Gore, Cole, Bamford, Dossetor, Barr, Dicarlo, Cork, and Lucas

9 Tyson J. Lasky R, Nuze C, White R. Growth and development of infants less than $1500 \mathrm{~g}$ fed bank human milk or premature formula (abstract). Pediatr Res 1981;15:549.

10 Atkinson SA, Bryan MH, Anderson GH. Human milk: difference in nitrogen concentration in milk from mothers of term and premature infants. $J$ Pediatr 1978;93:67-9.

11 Hibberd CM, Brooke OG, Carter ND, Haug M, Harzer G. Variation in the composition of breast milk during the first 5 weeks of lactation: implications for the feeding of preterm infants. Arch Dis Child 1982;57:658-62.

12 Lucas A. Availability of preterm milk. Lancet 1983;i:1045-6.

13 Jackson AA, Shaw JCL, Barber A, Golden MHN. Nitrogen metabolism in preterm infants fed human donor breast milk: the possible essentiality of glycine. Pediatr Res 1981;15:1454-61.

14 Reichman B, Chessex P, Putet G. et al. Diet, fat, accretion and growth in premature infants. $N$ Engl J Med 1981;305:1495-500.

15 Davis DP. Adequacy of expressed breast milk for early growth of preterm infants. Arch Dis Child 1977;52:296-301.

Correspondence to Dr A Lucas, Dunn Nutrition Unit, Downhams Lane, Milton Road, Cambridge CB4 1XJ.

Received 1 February 1984

A short report by Lewis and Smith on high volume milk feeds for preterm infants appears on page 779 of this issue. 